\title{
Oral Health Status of Institutionalized Individuals with Intellectual Disabilities in Lebanon
}

\author{
Hicham A. Diab', Ziad Salameh², Ghassan N. Hamadeh³, Genane Younes ${ }^{4}$, Fouad Ayoub \\ ${ }^{1}$ Department of Dental Public Health, Faculty of Dental Medicine, Lebanese University, Beirut, Lebanon. \\ ${ }^{2}$ Department of Research, Faculty of Dental Medicine, Lebanese University, Beirut, Lebanon. \\ ${ }^{3}$ Department of Family Medicine, Faculty of Medicine, American University of Beirut, Beirut, Lebanon. \\ ${ }^{4}$ Department of Statistics, ISSAE-Cnam, Beirut, Lebanon. \\ ${ }_{5}^{5}$ Department of Forensic Dentistry and Human Identification, Faculty of Dental Medicine, Lebanese University, Beirut, \\ Lebanon.
}

\author{
Corresponding Author: \\ Hicham A. Diab \\ Al Riyad, Beirut \\ Lebanon \\ Phone: 009613243777 \\ E-mail: hidiab@hotmail.com
}

\begin{abstract}
Objectives: To assess the dental status of institutionalized intellectually disabled individuals in Lebanon and the role of background and behavioural determinants.

Material and Methods: Oral health was recorded for 652 individuals (6, 12, 15 and 35 - 44 years old) using the decayed, missing and filled teeth/decayed and filled teeth (DMFT/dft) index. Data collected was statistically analysed with statistical significance set at $\mathrm{P}=0.05$.

Results: Overall, mean DMFT index score was 5.86 (SD 6); composed of 3.64 (SD 4.05) decayed (D) teeth; 1.71 (SD 4.38 ) missing (M) teeth; 0.87 (SD 2.51) filled (F) teeth. DMFT was highest in adults (12.71 [SD 7.43]) and had a large component of missing (6.24 [SD 7.02]) and filled (3.31 [SD 4.56]) teeth. DMFT scores ranged between 3.5 (SD 4.44) at 6 years and 4.8 (SD 4.52) at 15 years and the decayed component was the main contributor. In multivariate analyses, governorate of residence was statistically significantly $(\mathrm{P} \leq 0.040$ and $\mathrm{P} \leq 0.044)$ associated with $\mathrm{D}$ and DMFT, the degree of disability and caretaker educational level were statistically significantly $(P=0.009$ and $P=0.008)$ associated with $D$, oral hygiene practices were statistically significantly $(\mathrm{P} \leq 0.017 ; \mathrm{P}<0.001 ; \mathrm{P} \leq 0.017 ; \mathrm{P}<0.001)$ associated with $\mathrm{D}, \mathrm{M}, \mathrm{F}$ and $\mathrm{DMFT}$ and sugar consumption was statistically significantly $(\mathrm{P} \leq 0.03$ and $\mathrm{P} \leq 0.019)$ associated with $\mathrm{D}$ and DMFT.

Conclusions: In Lebanon, preventive and treatment programs to improve the oral health status of institutionalized intellectually disabled subjects are needed.
\end{abstract}

Keywords: disabled persons; DMF index; intellectual disability; Lebanon; oral health; teeth.

Accepted for publication: 29 March 2017

To cite this article:

Diab HA, Salameh Z, Hamadeh GN, Younes G, Ayoub F.

Oral Health Status of Institutionalized Individuals with Intellectual Disabilities in Lebanon

J Oral Maxillofac Res 2017;8(1):e4

URL: http://www.ejomr.org/JOMR/archives/2017/1/e4/v8n1e4.pdf

doi: $10.5037 /$ jomr.2017.8104 


\section{INTRODUCTION}

Intellectual disability is a developmental condition that is characterized by significant deficits in both intellectual functioning and adaptive behaviour including conceptual, social and practical skills [1]. Inhibiting participation in society for about 500 million people world-wide, intellectual disability is the most common developmental disorder affecting approximately $9-19 \%$ of the entire global population [2]. There is increasing evidence that oral health, which is crucial for proper mastication, aesthetics, communication, appearance and quality of life, is deficient in the mentally disabled population [36]. Aesthetically unacceptable and functionally inadequate dentitions affect self-esteem, confidence and psychological status []], which is often already compromised in individuals affected by developmental disabilities.

Poor oral health in the intellectually disabled has been attributed to several causes, including the individual's inability to achieve proper oral hygiene; the person's incapacity to express their pain and discomfort or by the parent or caregivers to evaluate their oral condition; and to the lack of resources, organizational support and knowledgeable professionals [8-11]. There appears to be a general agreement that dental treatment is one of the greatest unattended health needs of disabled individuals but these needs are nonetheless grossly under-estimated by both caregivers and the dental profession $[12,13]$. The reported associations between poor oral health in the intellectual disabled and the severity of the disability, parental education and socioeconomic status further highlight the social inequalities experienced by this vulnerable population $[14,15]$. It has been estimated that up to $80 \%$ of intellectually disabled individuals reside in developing countries [16]. Yet, despite recent growing research interest in the oral health of disabled individuals globally, the oral health and treatment needs of these populations in low income and developing countries have not nearly been adequately assessed [17]. Although there are at least 27,500 intellectually disabled individuals in Lebanon, an estimate that represents more than $28 \%$ of all disabled Lebanese individuals [18], the oral health conditions and treatment needs of this population have not previously been assessed.

The aim of the present study was to explore the dental status of institutionalized intellectually disabled individuals in Lebanon, and to investigate the associations between the number of decayed, filled and missing teeth with selected background and health related behaviours and characteristics.

\section{MATERIAL AND METHODS}

A national cross-sectional study was conducted between November 2015 and April 2016. Participants constituted of 652 institutionalized Lebanese individuals with intellectual disabilities residing across the 5 main Lebanese governorates and divided into 4 age categories: 6, 12, 15 and 35 - 44 years old. Ethical approval was obtained from the Ethical Research Committee of the Faculty of Medical Sciences at the Lebanese University in addition to the Ministry of Social Affairs in Lebanon (protocol no. 589, 2-215). Written consent was obtained from participants' parents, legal guardians or institution caretakers. Disabled persons who were absent or unable to cope with the clinical examination or whose lack of cooperation prevented the adequate collection of all measures of interest were excluded from the study.

\section{Data collection}

All 49 registered institutions for the intellectual disability across the Lebanese territory were approached and all but one, located in Mount Lebanon, approved participation in the study. Out of 703 institutionalized individuals belonging to the 4 targeted age groups, $652(92.7 \%)$ were examined. Data collection included two components: 1) a questionnaire filled by the participants' caretakers that collected information on background characteristics (age, sex, and governorate of residence), arrangement with the institution and characteristics of primary caretaker (relation to disabled person and education), type of disability and severity, oral hygiene practices (i.e. frequency of brushing) and dietary habits (i.e. consumption of sweets between meals) and 2) a clinical examination that assessed each participant's oral health status as per the World Health Organization (WHO) oral assessment form (1997) [19]. Clinical examinations were carried out by a trained dental practitioner with more than 15 years of experience in providing oral care to disabled individuals (the researcher), using appropriate protective infection control measures (disposable gloves, masks and sterile equipment). Each participant was seated under adequate room lighting and examined using sterile mouth mirrors and WHO probes.

\section{Measures}

Caries exposure was recorded using the decayedmissing-filled teeth (DMFT) index which records all teeth with known decay experience, 
i.e. untreated decay (D), missing teeth due to caries (M), and filled (F) teeth [19]. The notation decayed, filled teeth (dft) was used to distinguish primary teeth. This data constituted the four main outcomes of the study (per individual): the total numbers of 1) decayed; 2) missing and 3 ) filled teeth in addition to 4) the total number of decayed, missing and filled teeth (DMFT/dft index). The total number of missing teeth refers to missing permanent teeth only whereas the number of decayed and filled teeth and the DMFT/ dft index include pooled data for both primary and permanent teeth.

\section{Statistical analysis}

Descriptive statistics were generated to detail the distribution of the examined institutionalized participants across the various background, disability, health and nutritious practices. Bivariate analyses assessing associations between the possible predictors and the four main outcomes were conducted using simple linear regressions. Parametric data were expressed as mean and standard deviation (M $[\mathrm{SD}])$, degrees of freedom, $\mathrm{F}$ statistics and $\mathrm{P}$ values. Variables associated with the outcomes studied at $\mathrm{P}<0.2$ at the bivariate analyses were included in multiple regression analyses. The variable "teeth affected" was included to the multivariate models to differentiate between primary and permanent teeth. Regression coefficients, standard errors, 95\% confidence intervals (CI) and two-sided $\mathrm{P}$ values were generated for the multivariate regression models. Statistical significance level was defined at $\mathrm{P}=0.05$. The IBM ${ }^{\circledR}$ SPSS $^{\circledR}$ Statistics 20.0 and Stata/ SE 11.1 statistical packages were used to carry out all statistical analyses.

\section{RESULTS \\ Background characteristics}

A total of 652 institutionalized individuals, 142 $(21.8 \%)$ children aged 6 years, $232(35.6 \%)$ aged 12 years, $152(23.3 \%)$ aged 15 years and $126(19.3 \%)$ adults between the ages of 35 to 44 years were examined (Table 1). The majority of subjects were in institutions located in Mount Lebanon (44.8\%), followed by the North (18.9\%), Bekaa (18.1\%), the South (14.4\%) and finally Beirut (3.8\%). Most examined subjects were affected by mild retardation $(68.4 \%), 2 \%$ by severe and $29.4 \%$ by moderate retardation. The majority had a part-time arrangement with the institution $(89 \%)$ rather than a full-time arrangement, had a family member as their primary

Table 1. Percent distribution of examined institutionalized disabled persons by age, gender and oral health indices $(n=652)$

\begin{tabular}{|c|c|c|c|c|c|}
\hline \multirow{2}{*}{ Variable } & \multicolumn{5}{|c|}{ Age (years) } \\
\hline & 6 & 12 & 15 & $35-44$ & Total \\
\hline \multicolumn{6}{|c|}{ Gender, N (\%) } \\
\hline Male & $98(69)$ & $155(66.8)$ & $84(55.3)$ & $60(47.6)$ & $397(60.9)$ \\
\hline Female & $44(31)$ & 77 (33.2) & $68(44.7)$ & $66(52.4)$ & $255(39.1)$ \\
\hline Total & $142(21.8)$ & $232(35.6)$ & $152(23.3)$ & $126(19.3)$ & $652(100)$ \\
\hline \multicolumn{6}{|c|}{ Decayed, N (\%) } \\
\hline Mean (SD) & $3.28(4.45)$ & $3.9(3.56)$ & $4.01(4.28)$ & $3.17(4.11)$ & $3.64(4.05)$ \\
\hline Min; $\max$ & $0 ; 2$ & $0 ; 18$ & $0 ; 24$ & $0 ; 24$ & $0 ; 24$ \\
\hline \multicolumn{6}{|c|}{ Missinga, N (\%) } \\
\hline Mean (SD) & \multirow{2}{*}{ N/A } & $0.16(0.64)$ & $0.34(0.87)$ & $6.24(7.02)$ & $1.71(4.38)$ \\
\hline Min; $\max$ & & $0 ; 6$ & $0 ; 6$ & $0 ; 28$ & $0 ; 28$ \\
\hline \multicolumn{6}{|c|}{ Filled, N (\%) } \\
\hline Mean (SD) & $0.22(0.98)$ & $0.22(0.72)$ & $0.45(1.4)$ & $3.31(4.56)$ & $0.87(2.51)$ \\
\hline Min; $\max$ & $0 ; 6$ & $0 ; 5$ & $0 ; 1$ & $0 ; 18$ & $0 ; 18$ \\
\hline \multicolumn{6}{|c|}{ DMFT/dft, N (\%) } \\
\hline Mean (SD) & $3.5(4.44)$ & $4.28(3.72)$ & $4.80(4.52)$ & $12.71(7.43)$ & $5.86(6)$ \\
\hline Min; $\max$ & $0 ; 2$ & $0 ; 19$ & $0 ; 24$ & $0 ; 28$ & $0 ; 28$ \\
\hline
\end{tabular}

${ }^{\text {aF }}$ or subjects aged 6 years, the number of missing teeth is not recorded.

$\mathrm{dft}=$ total number of decayed and filled primary teeth; DMFT = total number of decayed, missing, filled permanent teeth; min = minimum; $\max =$ maximum; $\mathrm{SD}=$ standard deviation.

Mean refers to the mean number of teeth presenting with the specified condition per individual. 
caretaker $(89.7 \%)$ rather than an institution caretaker and this caretaker had completed only secondary education or less $(82.4 \%)$ compared to $17.6 \%$ with College or University education. Most subjects were not taking any medications for their disability at the time of their examination ( $81 \%)$.

\section{Oral health status}

Overall, the DMFT score was 5.86 (6); composed of 3.64 (4.05) decayed teeth, 1.71 (4.38) missing teeth and 0.87 (2.51) filled teeth (Table 1). There was a clear trend of increasing overall index with increasing age: increasing from a dft $=3.5$ (4.44) at 6 years to DMFT $=4.8(4.5)$ at 15 years and then to $12.71(7.43)$ at $35-44$ years. However, the number of untreated decays was actually lowest in the adult group (3.17 [4.11]) and the highest contributors to the overall DMFT in this age group were the missing (6.24 [7.02]) then the filled (3.31 [4.56]) teeth. On the other hand, the decayed teeth constituted the main component of the DMFT/dft score for all other age groups (Table 1).

\section{Oral hygiene and nutrition practices}

The majority of participants brushed $\geq 2$ /day independently (37.4\%) followed by those that brushed $1 /$ day without assistance $(27.5 \%)$ and only a minority (6\%) did not brush their teeth at all. Therefore, at least $64.9 \%$ of the sample brushed independently without receiving assistance. Similar proportions brushed either $\geq 2$ /day with help (10.6\%), 1/day with help $(7.8 \%)$ and rarely brushed their teeth $(10.7 \%)$. The majority consumed sweets between meals more than twice a day (32\%) and regularly consumed a combination of both home-cooked meals and fast food and pastries (64.1\%). Those consuming mainly home cooked meals were around one third (33.7\%) while those consuming predominantly only fast food and pastries were a small minority (2.2\%). Almost one fifth reported not to consume sugars between meals at all (17.2\%) and a similar proportion only $1 /$ day $(21.5 \%)$ whereas only $1.5 \%$ reported to rarely consume sugars between meals.

\section{Background predictors of oral health outcomes}

The distinction between primary and permanent teeth was not significant in any of the multivariate assessments of the combined or separate outcomes, suggesting that the predictors of these outcomes are similar regardless of the primary or permanent nature of the tooth $(\mathrm{P}>0.05)$ (Tables 2 and 3$)$.
Gender was not associated with any of the assessed outcomes, whereas age was a significant predictor of the number of missing teeth $(\mathrm{P}<0.001)$, filled teeth $(\mathrm{P}=0.009)$ and overall DMFT score $(\mathrm{P}<0.001)$. In all cases, only adults had significantly higher scores than children - 12 and 15 year olds having similar $\mathrm{D}, \mathrm{M}$ and DMFT scores to 6 year old children $(P>0.05)$ (Tables 2 and 3). Although the governorate of residence was not significantly associated with the total number of missing and filled teeth, it was a significant predictor of the total number of decayed teeth and the overall DMFT scores when controlling for all other characteristics $(\mathrm{P} \leq 0.044)$ (Tables 2 and 3). Controlling for all other variables, subjects residing in the South, Beirut and Bekaa all had significantly higher numbers of decayed teeth than those in the North (regression coefficient [Coef.] $=1.14$ to $2.26, \mathrm{P} \leq 0.006$ ) (Table 2). With respect to overall DMFT score, residents of Beirut had significantly worse DMFT scores than all those residing in any of the 4 other regions (Coef. $=-2.12$ to $-2.8 ; \mathrm{P} \leq 0.005)$ (Table 3 ).

\section{Predictors of oral health related to disability and arrangement}

The degree of intellectual disability was found to be a significant predictor only of the number of decayed teeth, and only when comparing moderate to mild disability in multivariate analysis (Table 2). When controlling for all other factors, subjects with moderate disability had significantly higher numbers of decayed teeth than those with mild disability (Coef. $=0.87 ; \mathrm{P}=0.009)($ Table 2$)$ but the comparison between severe and mild disability was not statistically significant $(P=0.561)$. Caretaker education was significantly associated with the number of decayed teeth but not with filled teeth, missing teeth or overall DMFT score. Subjects who had caretakers with College or University education had significantly lower numbers of decayed teeth than those whose caretakers had only secondary education or less (Coef. $=-1.12 ; \mathrm{P}=0.008)$ (Table 2$)$. Whether the primary caretaker was a parent or an institution caregiver and the type of arrangement with the institution did not significantly predict any of the four oral health outcomes $(\mathrm{P}>0.05)$ (Tables 2 and 3$)$.

\section{Oral health and nutrition practices as predictors of oral health}

Oral hygiene practices were significant predictors of all 4 oral health outcomes controlling for all remaining factors $(\mathrm{P}<0.05)$ (Tables 2 and 3 ). 
Table 2. Multivariate analysis showing associations between selected variables and number of decayed, missing and filled teeth separately $(\mathrm{n}=652)$

\begin{tabular}{|c|c|c|c|c|c|c|}
\hline \multirow{2}{*}{ Associated variables } & \multicolumn{2}{|c|}{ Decayed teeth } & \multicolumn{2}{|c|}{ Missing teeth } & \multicolumn{2}{|c|}{ Filled teeth } \\
\hline & Coef. $(95 \%$ CI) & P-value & Coef. $(95 \%$ CI) & P-value & Coef. $(95 \%$ CI) & P-value \\
\hline Constant & $4.21(2.48 ; 5.93)$ & $<0.001^{\mathrm{b}}$ & $8.19(6.59 ; 9.79)$ & $<0.001^{\mathrm{a}}$ & $-1.2(-2.04 ;-0.35)$ & $0.006^{\mathrm{b}}$ \\
\hline \multicolumn{7}{|l|}{ Teeth affected (Primary) } \\
\hline Permanent & $-2.99(-7.25 ; 1.27)$ & 0.168 & - & - & $-0.27(-2.78 ; 2.23)$ & 0.832 \\
\hline \multicolumn{3}{|c|}{ Age (6), years } & \multicolumn{2}{|c|}{ Age (12), years } & \multicolumn{2}{|c|}{ Age (6), years } \\
\hline 12 & $3.33(-0.9 ; 7.56)$ & 0.123 & - & - & $0.12(-2.37 ; 2.62)$ & 0.921 \\
\hline 15 & $3.67(-0.59 ; 7.94)$ & 0.091 & $0.12(-0.51 ; 0.76)$ & 0.703 & $0.36(-2.14 ; 2.88)$ & 0.774 \\
\hline $35-44$ & $2.45(-1.82 ; 6.73)$ & 0.261 & $4.97(4.23 ; 5.07)$ & $<0.001^{\mathrm{a}}$ & $3.34(0.82 ; 5.86)$ & $0.009^{b}$ \\
\hline \multicolumn{7}{|l|}{ Governorate (North) } \\
\hline South & $1.14(0.05 ; 2.22)$ & $0.04^{\mathrm{a}}$ & - & $\cdot$ & $0.22(-0.39 ; 0.84)$ & 0.477 \\
\hline Beirut & $2.26(0.66 ; 3.88)$ & $0.006^{\mathrm{b}}$ & - & - & $0.85(-0.13 ; 1.83)$ & 0.091 \\
\hline Mount Lebanon & $0.51(-0.33 ; 1.35)$ & 0.23 & - & - & $0.13(-0.42 ; 0.67)$ & 0.648 \\
\hline Bekaa & $1.43(0.41 ; 2.45)$ & $0.006^{\mathrm{b}}$ & - & - & $-0.23(-0.83 ; 0.37)$ & 0.456 \\
\hline \multicolumn{7}{|c|}{ Primary caretaker (Institution caretaker) } \\
\hline Family member & - & - & $-0.72(-1.64 ; 0.19)$ & 0.121 & - & - \\
\hline \multicolumn{7}{|c|}{ Education of caretaker (Secondary or less) } \\
\hline College/ University & $-1.12(-1.94 ;-0.3)$ & $0.008^{\mathrm{b}}$ & - & - & $-0.26(-0.21 ; 0.74)$ & 0.283 \\
\hline \multicolumn{7}{|l|}{ Use of medications (No) } \\
\hline Yes & - & - & - & - & $-0.15(-0.61 ; 0.29)$ & 0.5 \\
\hline \multicolumn{7}{|l|}{ Degree of disability (Mild) } \\
\hline Moderate & $0.87(0.22 ; 1.53)$ & $0.009^{\mathrm{b}}$ & $-0.29(-0.9 ; 0.32)$ & 0.347 & - & - \\
\hline Severe & $0.62(-1.47 ; 2.7)$ & 0.561 & $1.5(-0.3 ; 3.3)$ & 0.103 & - & - \\
\hline \multicolumn{7}{|c|}{ Frequency of brushing (No use) } \\
\hline Rarely & $-0.61(-2.12 ; 0.91)$ & 0.43 & $-7.5(-8.9 ;-6.05)$ & $<0.001^{\mathrm{a}}$ & $1.2(0.32 ; 2.08)$ & $0.008^{\mathrm{b}}$ \\
\hline 1/day with help & $-1.94(-3.53 ;-0.03)$ & $0.017^{\mathrm{a}}$ & $-6.5(-8.17 ;-4.88)$ & $<0.001^{\mathrm{a}}$ & $1.14(0.21 ; 2.08)$ & $0.017^{\mathrm{a}}$ \\
\hline 1/day without help & $-1.68(-3.02 ;-0.03)$ & $0.013^{\mathrm{a}}$ & $-7.79(-9.05 ;-6.53)$ & $<0.001^{\mathrm{a}}$ & $1.55(0.77 ; 2.32)$ & $<0.001^{\mathrm{b}}$ \\
\hline$\geq 2 /$ day with help & $-2.1(-3.65 ;-0.54)$ & $0.008^{\mathrm{b}}$ & $-7.5(-9.11 ;-5.89)$ & $<0.001^{\mathrm{a}}$ & $1.35(0.45 ; 2.25)$ & $0.003^{\mathrm{b}}$ \\
\hline$\geq 2 /$ day without help & $-1.87(-3.21 ;-0.54)$ & $0.006^{\mathrm{b}}$ & $-7.67(-8.93 ;-6.41)$ & $<0.001^{\mathrm{a}}$ & $1.61(0.86 ; 2.37)$ & $<0.001^{\mathrm{b}}$ \\
\hline \multicolumn{7}{|c|}{ Type of meals consumed (Home-cooked) } \\
\hline Fast food and pastries & $1.13(-0.95 ; 3.21)$ & 0.287 & - & - & - & - \\
\hline Combination of both & $-0.39(-1.13 ; 0.36)$ & 0.308 & - & - & - & - \\
\hline \multicolumn{7}{|c|}{ Sweets between meals (No consumption) } \\
\hline Rarely & $1.86(-0.57 ; 1.36)$ & 0.134 & $-2.18(-4.44 ; 0.07)$ & 0.058 & - & - \\
\hline 1/day & $0.4(0.1 ; 2.04)$ & 0.416 & $-0.38(-1.28 ; 0.52)$ & 0.409 & - & - \\
\hline 2/day & $1.07(2.14 ; 4.13)$ & $0.03^{\mathrm{a}}$ & $0.39(-0.48 ; 1.26)$ & 0.381 & - & - \\
\hline$>2 /$ day & $3.13(2.48 ; 5.93)$ & $<0.001^{\mathrm{b}}$ & $0.42(-0.42 ; 1.26)$ & 0.323 & - & - \\
\hline $\mathrm{F}(22,629)$ & \multicolumn{2}{|l|}{7.1} & \multicolumn{2}{|l|}{39.06} & \multicolumn{2}{|l|}{15.14} \\
\hline Prob $>$ F & \multicolumn{2}{|l|}{$<0.001^{\mathrm{b}}$} & \multicolumn{2}{|l|}{$<0.001^{\mathrm{a}}$} & \multicolumn{2}{|l|}{$<0.001^{\mathrm{b}}$} \\
\hline R-squared & \multicolumn{2}{|l|}{0.1989} & \multicolumn{2}{|l|}{0.5249} & \multicolumn{2}{|l|}{0.2632} \\
\hline Adjusted $\mathrm{R}^{2}$ & 0.1709 & & 0.5114 & & 0.2458 & \\
\hline RMSE & 3.687 & & 3.0669 & & 2.1762 & \\
\hline
\end{tabular}

a Statistically significant at $\mathrm{P} \leq 0.05$ (Multivariate analysis).

${ }^{\mathrm{b} S t a t i s t i c a l l y ~ s i g n i f i c a n t ~ a t ~} \mathrm{P}<0.01$ (Multivariate analysis).

Coef. $=$ regression coefficient $\mathrm{CI}=$ confidence interval; $\mathrm{F}=$ the model's degrees of freedom and residual degrees of freedom; RMSE $=$ root-mean-square-error.

Base refers to the base outcome all other categories are compared to. 
Table 3. Multivariate analysis showing associations between selected variables and number of decayed, missing and filled teeth $(\mathrm{n}=652)$

\begin{tabular}{|c|c|c|c|}
\hline \multirow[t]{2}{*}{ Associated variables } & \multicolumn{3}{|c|}{$\begin{array}{c}\text { Decayed, missing and filled } \\
\text { teeth }\end{array}$} \\
\hline & Coef. & $95 \% \mathrm{CI}$ & P-value \\
\hline Constant & 10.5 & $7.02 ; 13.98$ & $<0.001^{\mathrm{b}}$ \\
\hline \multicolumn{4}{|l|}{ Teeth affected (Primary) } \\
\hline Permanent & -2.38 & $-7.56 ; 2.8$ & 0.367 \\
\hline \multicolumn{4}{|l|}{ Age (6), years } \\
\hline 12 & 3.14 & $-2 ; 8.28$ & 0.231 \\
\hline 15 & 3.82 & $-1.37 ; 9$ & 0.149 \\
\hline $35-44$ & 10.78 & $5.56 ; 15.99$ & $<0.001^{\mathrm{b}}$ \\
\hline \multicolumn{4}{|l|}{ Governorate (Beirut) } \\
\hline North & -2.8 & $-4.76 ;-0.83$ & $0.005^{\mathrm{b}}$ \\
\hline South & -2.22 & $-4.33 ;-0.12$ & $0.038^{\mathrm{a}}$ \\
\hline Mount Lebanon & -2.31 & $-4.26 ;-0.35$ & $0.021^{\mathrm{a}}$ \\
\hline Bekaa & -2.12 & $-4.18 ;-0.06$ & $0.044^{\mathrm{a}}$ \\
\hline \multicolumn{4}{|l|}{ Arrangement (Full time) } \\
\hline Part time & -1.36 & $-2.89 ; 0.17$ & 0.081 \\
\hline \multicolumn{4}{|c|}{ Education of caretaker (Secondary or less) } \\
\hline College/University & -1.14 & $-2.3 ; 0.21$ & 0.054 \\
\hline \multicolumn{4}{|l|}{ Degree of disability (Mild) } \\
\hline Moderate & 0.78 & $-0.08 ; 1.65$ & 0.077 \\
\hline Severe & 1.41 & $-1.12 ; 3.96$ & 0.274 \\
\hline \multicolumn{4}{|l|}{ Use of medications (No) } \\
\hline Yes & -0.86 & $-1.87 ; 0.16$ & 0.098 \\
\hline \multicolumn{4}{|c|}{ Frequency of brushing (No use) } \\
\hline Rarely & -5.1 & $-6.94 ;-3.81$ & $<0.001^{\mathrm{b}}$ \\
\hline 1/day with help & -5.75 & $-7.70 ;-3.81$ & $<0.001^{\mathrm{b}}$ \\
\hline 1/day without help & -6.27 & $-7.89 ;-4.64$ & $<0.001^{\mathrm{b}}$ \\
\hline$\geq 2 /$ day with help & -6.32 & $-8.21 ;-4.43$ & $<0.001^{\mathrm{b}}$ \\
\hline$\geq 2$ day without help & -6.34 & $-7.97 ;-4.64$ & $<0.001^{\mathrm{b}}$ \\
\hline \multicolumn{4}{|c|}{ Type of meals consumed (Home-cooked) } \\
\hline Fast food and pastries & 2.38 & $-0.16 ; 4.93$ & 0.066 \\
\hline Combination of both & 0.03 & $-0.91 ; 0.98$ & 0.944 \\
\hline \multicolumn{4}{|c|}{ Sweets between meals (No consumption) } \\
\hline Rarely & 0.84 & $-2.13 ; 3.81$ & 0.58 \\
\hline 1/day & 0.6 & $-0.58 ; 1.78$ & 0.319 \\
\hline $2 /$ day & 1.41 & $0.23 ; 2.6$ & $0.019^{\mathrm{a}}$ \\
\hline$>2 /$ day & 3.13 & $1.93 ; 4.34$ & $<0.001^{\mathrm{b}}$ \\
\hline $\mathrm{F}(24,627)$ & \multicolumn{3}{|c|}{22.46} \\
\hline Prob $>F$ & \multicolumn{3}{|c|}{$<0.001^{\mathrm{b}}$} \\
\hline R-squared & \multicolumn{3}{|c|}{0.4623} \\
\hline Adjusted $\mathrm{R}^{2}$ & \multicolumn{3}{|c|}{0.4417} \\
\hline RMSE & \multicolumn{3}{|c|}{4.4817} \\
\hline
\end{tabular}

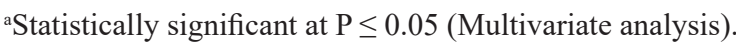

${ }^{b}$ Statistically significant at $\mathrm{P}<0.01$ (Multivariate analysis).

Coef. $=$ regression coefficient; $\mathrm{CI}=$ confidence interval; $\mathrm{F}=$ the model's degrees of freedom and residual degrees of freedom; RMSE = root-mean-square-error.

Base refers to the base outcome all other categories are compared to.
All levels of brushing, with or without help, were associated with significantly better outcomes for decayed, missing, filled teeth and for overall DMFT score. Receiving assistance during brushing was associated with lower overall number of decayed teeth both in individuals brushing 1 /day (Coef. $=-1.94$ with help compared to -1.68 without help) and in those brushing $\geq 2$ /day (Coef. $=-2.1$ with help compared to -1.87 without help) (Table 2). For the number of filled teeth, receiving help during brushing was associated with lower total numbers of restorations both when subjects brushed 1/day (Coef. $=1.55$ without help compared to 1.14 with help) or $\geq 2 /$ day (Coef. $=1.61$ without help compared to 1.35 with help) (Table 2). When controlling for tooth brushing and all other factors, the type of meals predominantly consumed (fast food or home-cooked) was not significantly associated with either decayed, missing, filled teeth or overall index. The consumption of sugars between meals, on the other hand, was a significant predictor of the number of carious teeth and the overall DMFT score $(\mathrm{P}<0.001)$ (Tables 2 and 3$)$. Both for carious teeth and DMFT index, sweet consumption needed to be $2 /$ day or more to be associated with significantly worse oral health compared to no sugar consumption between meals: decayed teeth, Coef. $=1.07, \mathrm{P}=0.03$ for $2 /$ day and Coef. $=3.13, \mathrm{P}<0.001$ for $>2 /$ day (Table 2); and DMFT score, Coef. $=1.41, \mathrm{P}=0.019$ for $2 /$ day and Coef. $=3.13, \mathrm{P}<0.001$ for $>2$ /day (Table 3).

\section{DISCUSSION}

In a first assessment of its kind in Lebanon, our study highlights the presence of poor oral health conditions in an intellectually disabled population in Lebanon - corroborating the results of several global studies associating poor oral health with intellectual disability $[\underline{5}, \underline{20}]$. The relatively high DMFT scores described in our sample of children, adolescents and adults, averaging a value of almost 6 teeth, are similar to reports on intellectually disabled persons in several other populations [6,21-25]. The high caries activity noted in our sample may be attributed to their difficulty in maintaining oral hygiene, poor muscular co-ordination, and muscle weakness interfering with routine oral hygiene procedures [26]. Although assessments of DMFT scores in younger age groups comparable to our 6 year old sample are very scarce, the oral health situation of this age group in our Lebanese sample was worse than reported in a Brazilian sample of $5-8$ year old children [27]. 
Jain et al. [14] also report much lower DMFT scores in their assessed population of Indian children and young adults: 1.5 for 12 - 15 year olds and 2.75 for 26 - 30 year olds, and an overall mean of 2 [14]. This finding may however be explained by the fact that the entire sample was collected from one special needs school which, according to the authors, likely provides very good oral health care and monitoring to their beneficiaries. Even lower scores were reported in another study on Indian children from special schools, with a mean DMFT of only 0.5 teeth reported [29]. However, the scarcity of such studies in comparison to the vast literature reporting poor DMFT scores suggests an overall poor oral health among the intellectually disabled globally, albeit suggesting the ability to limit disease progression in well-controlled settings and with special care by appropriately trained personnel.

As in our sample, several researchers have noted that the predominant contributor to the DMFT score in various disabled populations was the decayed component [23-25,29-31], although missing teeth were also reported to be significant contributors, especially in adult populations and with increasing disability severity [22]. The low contribution of the filled component observed in our study is an observation that has also been reported by previous studies and may be reflective of the overall lower provision of dental treatment to the intellectually disabled than the general population (and hence the greater progression of carious lesions) and also to the tendency for extractions rather than restorations due to difficulties in the behavioural management of this population $[\underline{5}, \underline{25}, \underline{32}]$. Exceptionally, in an assessment of more than 4,000 adult intellectually disabled persons in the United States, Morgan et al. [ $\underline{6}]$ reported very low scores for decayed teeth and a high predominance of filled teeth. However, all assessed subjects were part of a large state-wide program specifically established to serve persons with special needs, thereby biasing these individuals towards greater access to and benefit from dental health care [6].

Our results bring additional data to previous research that proposes a number of individual, carer and social barriers contributing to oral health problems in the intellectually disabled $[\underline{5}, \underline{33}]$. Several researchers have linked greater disable severity with poorer caries scores [24,34], a finding that was present in our sample but only in association with the number of decayed teeth as a separate entity. Although individuals with moderate disability had significantly more decayed teeth compared to those with mild disability, the comparison with severe disability failed to reach statistical significance, possibly because of the small sample size (severe disability comprising only $2 \%$ of the assessed sample). The association between age and higher DMFT scores observed in our sample has also been commonly reported in previous studies $[\underline{6}, \underline{14}, \underline{23}, \underline{27}]$ and the lack of association with gender has similarly been suggested [14]. This trend was noted in our evaluation of overall DMFT scores but also in evaluating the predictors of the decayed, missing and filled components separately, which, to our knowledge, have not previously been assessed as separate entities.

Notably, two modifiable behavioural factors were associated with poor DMFT scores in our sample: oral hygiene practices and the consumption of sweets between meals, which were similarly predictors of the number of decayed and missing teeth separately. Our observations support previous research on this topic were both oral hygiene practices and the degree of diet carcinogenicity predicted DMFT scores $[\underline{8}, \underline{14}, \underline{23}]$. Unfortunately, our results and the literature suggest that in the majority of cases, the oral health care of this risky population is often lacking. At least two thirds of our sample brushed their teeth independently without receiving any assistance from their caretakers, a phenomenon which is in agreement with reports from several other previous studies reporting $[\underline{23}, \underline{26}, \underline{32}, \underline{36}]$. Although this may be a manifestation of non-cooperation by the disabled persons, it also reflects poorly on the level of awareness and/or motivation among parents and caretakers regarding the importance of oral hygiene and their role as caretakers in its maintenance. The associations observed in our study between assisted brushing and lower numbers of decayed teeth and higher number of filled teeth emphasize the benefit of receiving assistance during brushing both in maintaining oral hygiene/plaque removal and perhaps in identifying carious lesions and therefore seeking treatment for the disabled person.

Although poor oral hygiene in the disabled has previously been associated with the type of caregiver and with institutional arrangement [ $]$ ], none of the outcomes separately or combined were significantly associated with the type of arrangement with the institution (part-time or fulltime) or whether the caretaker was a parent or an institution caregiver. Caretaker education, on the other hand, was significantly associated with the total number of decayed teeth and is a finding that echoes the associations reported between DMFT scores and the level of education of the parents in previous studies [14]. Previous studies have similarly highlighted the importance of socio-economic 
status (SES) as a predictor of oral health in intellectual disabled individuals, including variables such as parent education, geographical location, lack of organizational support and overall SES category $[\underline{6}, \underline{12}, \underline{36}]$. Supporting previous research, our results similarly highlight significant socioeconomic inequalities in Lebanon with respect to oral health indices regardless of oral hygiene and nutrition factors. Increased numbers of decayed teeth were noted in subjects residing in the South, Bekaa and Beirut compared to those in the North, the highest scores recorded in the capital city Beirut. Overall DMFT score was similarly associated with the geographical location of the institution, subjects in Beirut suffering from significantly higher DMFT scores than those from all other Lebanese governorates.

The geographical location in our sample is likely to be a proxy variable for underlying socioeconomic disadvantages that may include parental education, financial stability and inaccessibility to dental services, but the interesting finding of poor oral hygiene indices specifically in the capital is a finding that requires further investigation prior to generalization. It must be noted that only $5 \%$ of the entire sample were from institutions in Beirut and all attended one institution. It is possible that specific factors relating to this institution are related to beneficiaries of lower socio-economic status and the results may not be generalized to the whole of Beirut. The increased number of decayed teeth noted in the governorates of the South and Bekaa, on the other hand, may be truly reflective of a wider scope of underlying social disadvantages and justify the implementation of targeted intervention programs that provide relief from existing disease and prevention of future disease. There is a definite need for preventive and treatment programs aiming to improve the oral health status of this vulnerable population. Research suggests that individuals with intellectual disability would benefit from more frequent oral health assessments than would otherwise be needed in the general population [33].

The significant role of behavioural factors disclosed by our study, including assisted oral hygiene and reduced sugar intake emphasizes the need to educate parents and caregivers on their active role in participating in preventive programs to ensure appropriate supervision of daily oral hygiene. Raising caretaker awareness regarding the importance of supervised tooth brushing and limiting the intake of cariogenic substrates is a crucial step towards limiting the progression of carious diseases in the intellectually disabled population.

It must be noted that despite the high response rate and large coverage of almost all registered institutions for the intellectual disability in Lebanon, our results cannot be generalized to the entire population of non-institutionalized intellectually disabled subjects in Lebanon. The limitation of target age groups to ages 6, 12, 15 and 35 - 44 years, although for the purposes of practicality and comparability with similar studies, also limits generalizability to other generations. Future studies both including wider ages groups and comparing the institutionalized to the noninstitutionalized are imperative towards understanding the true state of oral health and dental treatment needs in the Lebanese mentally disabled population at large.

\section{CONCLUSIONS}

Institutionalized individuals with intellectual disabilities in Lebanon presented with poor oral health scores. There was a clear trend of increasing overall DMFT index with increasing age, characterized by low levels of untreated decayed teeth and predominance of missing teeth followed by filled teeth. Decayed teeth were the main contributors to the index in the younger groups. Geographical location was a significant predictor of oral health outcomes suggesting socioeconomic inequalities. Increased brushing frequency predicted lower numbers of decayed, filled and missing teeth separately and overall DMFT. Assisted brushing was associated with lower numbers of decayed and filled teeth. Increased sugar consumption between meals predicted worse scores for decayed teeth and DMFT but type of meals consumed showed no association.

\section{ACKNOWLEDGMENT AND DISCLOSURE STATEMENTS}

The authors would like to thank the staff at ChartsResearch Design and Biostatistics for their help in the statistical analysis and write up of the study.

The authors declare no potential conflicts of interest with respect to the authorship and/or publication of this article. 


\section{REFERENCES}

1. American Psychiatric Association. Diagnostic and statistical manual of mental disorders: DSM-V. 5th ed. Washington (DC): American Psychiatric Association; 2013. p. 31.

2. Demyttenaere K, Bruffaerts R, Posada-Villa J, Gasquet I, Kovess V, Lepine JP, Angermeyer MC, Bernert S, de Girolamo G, Morosini P, Polidori G, Kikkawa T, Kawakami N, Ono Y, Takeshima T, Uda H, Karam EG, Fayyad JA, Karam AN, Mneimneh ZN, Medina-Mora ME, Borges G, Lara C, de Graaf R, Ormel J, Gureje O, Shen Y, Huang Y, Zhang M, Alonso J, Haro JM, Vilagut G, Bromet EJ, Gluzman S, Webb C, Kessler RC, Merikangas KR, Anthony JC, Von Korff MR, Wang PS, Brugha TS, Aguilar-Gaxiola S, Lee S, Heeringa S, Pennell BE, Zaslavsky AM, Ustun TB, Chatterji S; WHO World Mental Health Survey Consortium.. Prevalence, severity, and unmet need for treatment of mental disorders in the World Health Organization World Mental Health Surveys. JAMA. 2004 Jun 2;291(21):2581-90. [Medline: 15173149] [doi: 10.1001/jama.291.21.2581]

3. Pistorius J, Horn JG, Pistorius A, Kraft J. Oral health-related quality of life in patients with removable dentures. Schweiz Monatsschr Zahnmed. 2013;123(11):964-71; 955. English, German. [Medline: 24420442]

4. Gomes MC, Pinto-Sarmento TC, Costa EM, Martins CC, Granville-Garcia AF, Paiva SM. Impact of oral health conditions on the quality of life of preschool children and their families: a cross-sectional study. Health Qual Life Outcomes. 2014 Apr 18;12:55. doi: 10.1186/1477-7525-12-55. [Medline: 24745700] [PMC free article: 4002905] [doi: 10.1186/1477-7525-12-55]

5. Anders PL, Davis EL. Oral health of patients with intellectual disabilities: a systematic review. Spec Care Dentist. 2010 May-Jun;30(3):110-7. [Medline: 20500706] [doi: 10.1111/j.1754-4505.2010.00136.x]

6. Morgan JP, Minihan PM, Stark PC, Finkelman MD, Yantsides KE, Park A, Nobles CJ, Tao W, Must A. The oral health status of 4,732 adults with intellectual and developmental disabilities. J Am Dent Assoc. 2012 Aug;143(8):838-46. [Medline: 22855898] [PMC free article: 4527687] [doi: 10.14219/jada.archive.2012.0288]

7. Fiske J, Davis DM, Frances C, Gelbier S. The emotional effects of tooth loss in edentulous people. Br Dent J. 1998 Jan 24;184(2):90-3; discussion 79. [Medline: 9489217] [doi: 10.1038/sj.bdj.4809551]

8. Oredugba FA, Akindayomi Y. Oral health status and treatment needs of children and young adults attending a day centre for individuals with special health care needs. BMC Oral Health. 2008 Oct 22;8:30. [Medline: 18945371] [PMC free article: 2579283] [doi: 10.1186/1472-6831-8-30]

9. Sanders C, Kleinert HL, Boyd SE, Herren C, Theiss L, Mink J. Virtual patient instruction for dental students: can it improve dental care access for persons with special needs? Spec Care Dentist. 2008 Sep-Oct;28(5):205-13. [Medline: 18782198] [doi: 10.1111/j.1754-4505.2008.00038.x]

10. American Academy on Pediatric Dentistry Council on Clinical Affairs. Guideline on management of dental patients with special health care needs. Pediatr Dent. 2008-2009;30(7 Suppl):107-11. [Medline: 19216407]

11. Lin JD, Wu CL, Lin PY, Lin LP, Chu CM. Early onset ageing and service preparation in people with intellectual disabilities: institutional managers' perspective. Res Dev Disabil. 2011 Jan-Feb;32(1):188-93. [Medline: 20970957] [doi: 10.1016/j.ridd.2010.09.018]

12. Anderson LL, Humphries K, McDermott S, Marks B, Sisirak J, Larson S . The state of the science of health and wellness for adults with intellectual and developmental disabilities. J Intellect Dev Disabil. 2013;51(5):385-398. [Medline: 24303825] [PMC free article: 4677669] [doi: 10.1352/1934-9556-51.5.385]

13. Anderson LL, Humphries K, McDermott S, Marks B, Sisirak J, Larson S. The state of the science of health and wellness for adults with intellectual and developmental disabilities. Intellect Dev Disabil. 2013 Oct;51(5):385-98. [Medline: 24303825] [PMC free article: 4677669] [doi: 10.1352/1934-9556-51.5.385]

14. Jain M, Mathur A, Sawla L, Choudhary G, Kabra K, Duraiswamy P, Kulkarni S. Oral health status of mentally disabled subjects in India. J Oral Sci. 2009 Sep;51(3):333-40. [Medline: 19776499] [doi: 10.2334/josnusd.51.333]

15. Kumar S, Sharma J, Duraiswamy P, Kulkarni S. Determinants for oral hygiene and periodontal status among mentally disabled children and adolescents. J Indian Soc Pedod Prev Dent. 2009 Jul-Sep;27(3):151-7. [Medline: 19841546] [doi: 10.4103/0970-4388.57095]

16. Matson JL, Shoemaker ME. Psychopathology and intellectual disability. Curr Opin Psychiatry. 2011 Sep;24(5):367-71. [Medline: 21150621] [doi: 10.1097/YCO.0b013e3283422424]

17. Hughes MJ, Gazmararian JA. The relationship between income and oral health among people with intellectual disabilities: a global perspective. Spec Care Dentist. 2015 May 1. [Medline: 25939799] [doi: 10.1111/scd.12114]

18. Lebanese Ministry of Social Affairs. Unofficial report of the distribution of handicapped individuals in Lebanon by governorate, age and type of handicap. January 31, 2015.

19. World Health Organization. Oral Health Surveys - Basic methods. 4th ed. Geneva, Switzerland: WHO; 1997. [URL: http://www.who.int/publications/en/]

20. Cheng RH, Leung WK, Corbet EF, King NM. Oral health status of adults with Down syndrome in Hong Kong. Spec Care Dentist. 2007 Jul-Aug;27(4):134-8. [Medline: 17972443] [doi: 10.1111/j.1754-4505.2007.tb00335.x]

21. Shukla D, Bablani D, Chowdhry A, Jafri Z, Ahmad N, Mishra S. Oral health status and dental caries experience inmentally challenged individuals. Ann Public Health Res. 2014;1(2):1008. [URL: https://www.jscimedcentral.com/PublicHealth/] 
22. Ozgul O, Dursun E, Ozgul BM, Kartal Y, Coskunses FM, Kocyigit ID, Tözüm TF. The impact of handicap severity on oral and periodontal status of patients with mental retardation. J Contemp Dent Pract. 2014 Mar 1;15(2):218-22. [Medline: 25095847] [doi: 10.5005/jp-journals-10024-1518]

23. Chang J, Lee JH, Son HH, Kim HY. Caries risk profile of Korean dental patients with severe intellectual disabilities. Spec Care Dentist. 2014 Jul-Aug;34(4):201-7. [Medline: 25039380] [doi: 10.1111/scd.12047]

24. Ilić S, Djeri A, Pašagić L, Pavlić V, Janković O. Oral health status of people with mental disabilities in the municipality of Banja Luka. Stomatološki glasnik Srbije. 2014;61(1):21-9. [doi: 10.2298/SGS1401021I]

25. Oliveira JS, Prado Júnior RR, de Sousa Lima KR, de Oliveira Amaral H, Moita Neto JM, Mendes RF. Intellectual disability and impact on oral health: a paired study. Spec Care Dentist. 2013 Nov-Dec;33(6):262-8. [Medline: 24164223] [doi: $10.1111 / \mathrm{scd} .12015$ ]

26. Vyas HA, Damle SG. Comparative study of oral health status of mentally sub-normal, physically handicapped, juvenile delinquents and normal children of Bombay. J Indian Soc Pedod Prev Dent. 1991 Mar;9(1):13-6. [Medline: 1840302]

27. Batista LR, Moreira EA, Rauen MS, Corso AC, Fiates GM. Oral health and nutritional status of semi-institutionalized persons with mental retardation in Brazil. Res Dev Disabil. 2009 Sep-Oct;30(5):839-46. [Medline: 19062253] [doi: 10.1016/j.ridd.2008.10.004]

28. Pramila M, Hiremath SS. Oral health status of handicapped children attending special schools in Bangalore city. Int J Contemp Dent. 2011;2(1):55-8. [URL: http://www.edentj.com/index.php/ijcd/]

29. Kavvadia K, Gizani S, Mamali S, Nassika M. Oral health status of teenagers and young adults with intellectual impairment in Athens, Greece. J Disabil Oral Health. 2008 Jun;9(2):63-9. [URL: http://www.bsdh.org ]

30. Turner S, Sweeney M, Kennedy C, Macpherson L. The oral health of people with intellectual disability participating in the UK Special Olympics. J Intellect Disabil Res. 2008 Jan;52(Pt 1):29-36. [Medline: 18173570] [doi: 10.1111/j.1365-2788.2007.00971.x]

31. Rupinder B, Namrata M. The oral health status and treatment needs of institutionalized and non institutionalized disabled children in Navi Mumbai, India. Int J Contemprar Med Res. 2016 Apr;3(4):1041-5. [URL: http://www.ijcmr.com]

32. Shaw L, Maclaurin ET, Foster TD. Dental study of handicapped children attending special schools in Birmingham, UK. Community Dent Oral Epidemiol. 1986 Feb;14(1):24-7. [Medline: 2937607] [doi: 10.1111/j.1600-0528.1986.tb01488.x]

33. Fisher K. Is there anything to smile about? A review of oral care for individuals with intellectual and developmental disabilities. Nurs Res Pract. 2012;2012:860692. [doi: 10.1155/2012/860692]

34. Chhajed S, Bhambhani G, Agarwal R, Balsaraf S. Impact of various extra-oral factors on caries experience among mentally disabled children residing in Bhopal city, central India: A cross-sectional study. J Indian Soc Pedod Prev Dent. 2016 Jul-Sep;34(3):285-90. [Medline: 27461815] [doi: 10.4103/0970-4388.186744]

35. Storhaug K. Caries experience in disabled pre-school children. Acta Odontol Scand. 1985 Aug;43(4):241-8. [Medline: 2932882] [doi: 10.3109/00016358509046504]

36. Kadam NS, Patil R, Gurav AN, Patil Y, Shete A, Naik Tari R, Agarwal D, Shirke DT, Jadhav P. Oral hygiene status, periodontal status, and periodontal treatment needs among institutionalized intellectually disabled subjects in Kolhapur district, Maharashtra, India. J Oral Dis. 2014 Dec;2014:535316. [doi: 10.1155/2014/535316]

\section{To cite this article:}

Diab HA, Salameh Z, Hamadeh GN, Younes G, Ayoub F.

Oral Health Status of Institutionalized Individuals with Intellectual Disabilities in Lebanon

J Oral Maxillofac Res 2017;8(1):e4

URL: http://www.ejomr.org/JOMR/archives/2017/1/e4/v8n1e4.pdf

doi: $10.5037 /$ jomr.2017.8104

Copyright (C) Diab HA, Salameh Z, Hamadeh GN, Younes G, Ayoub F. Published in the JOURNAL OF ORAL \& MAXILLOFACIAL RESEARCH (http://www.ejomr.org), 31 March 2017.

This is an open-access article, first published in the JOURNAL OF ORAL \& MAXILLOFACIAL RESEARCH, distributed under the terms of the Creative Commons Attribution-Noncommercial-No Derivative Works 3.0 Unported License, which permits unrestricted non-commercial use, distribution, and reproduction in any medium, provided the original work and is properly cited. The copyright, license information and link to the original publication on (http://www.ejomr.org) must be included. 